\title{
Research on Strategies of Teaching Japanese for Chinese Students based on Cultural Differences between China and Japan
}

\author{
$\mathrm{Ze} X \mathrm{u}^{1, \mathrm{a}}$ \\ ${ }^{1}$ Foreign Languages' College, Beihua University, Jilin 132013, China; \\ azexu-007@163.com
}

Keywords: Cultural Differences between China and Japan, Strategies, Teaching Japanese, Cross-cultural Communication.

\begin{abstract}
The strategies of teaching Japanese were taken in Cross-cultural communication between China and Japan, and the cultural similarities and differences between the two countries were analyzed. Then understand the inherent culture characteristics, national spirit framework and ethnic characteristics of Japanese, recognize the cultural mixing and conflict between China and Japan clearly, thus the awareness of intercultural communication will be enhanced.
\end{abstract}

\section{Introduction}

The world's historical and cultural development of each country are not isolated self-development and reproduction of these countries and other countries to carry out economic and cultural exchanges, learn from each other, influence each other, complement each other, mutual penetration. No country needs to draw a steady stream of outstanding foreign culture, absorb foreign culture in essence part, will eventually own culture and foreign cultures together. Clearly, the role of cross-cultural communication is important, it affects all countries of the socio-economic and cultural development. Dawn of the twenty-first century, cross-cultural phenomenon in various countries reached its peak, at the same time, problems have emerged, when people from different countries to communicate, because the culture, values, lifestyle, language expressions, social customs differences lead to misunderstanding of the phenomenon abound. From this study the cultural differences between different countries is of great significance.

Relations between China and Japan, as "narrow strip of water," described as the two countries across the sea from the point of view location, AC Historically, there have been two thousand years of history of exchanges, we can see the relationship between the two countries It is fairly tight. Since ancient times, the profound Chinese civilization on the social and historical development of Japan had a subtle effect. After the Meiji Restoration, Japan rapidly developed, became the only Eastern countries made early modern country. After World War II, Japan undone, rise again, only this ranks in the United States as the world's second economic power. With the development of society and economy, but also accelerated the exchange between China and Japan, especially since the normalization of diplomatic relations between the two countries in political and economic aspects of the increasingly frequent, and language and cultural barriers have become hinder mutual exchanges key. In order to eliminate barriers and promote the further development of bilateral economic and trade, culture, and they set off a craze for learning Chinese. Of course. It also gives Chinese language teaching presents new challenges, namely how to achieve effective teaching Chinese Foreign according to the Japanese language, cultural characteristics.

In recent years, with the intensification of the Diaoyu Islands territorial issue, the Japanese government does not face up to history and distorting facts, tampering with textbooks, Yasukuni Shrine, relations between China and Japan dropped to the freezing point, the two sides are each other people hold deep grudges, it really makes people sad! This addition to the different core interests of China and Japan, but also China and Japan since ancient times precipitated deep culture have a great relationship. Not only do we lack the deep understanding of Japanese culture and a deep understanding, lack of corresponding countermeasures. If such a situation be allowed to continue, we 
must suffer a great deal, the lessons of history and experience tell have told us. Therefore, Sino-Japanese Intercultural Communication analyze and propose some solutions strategy to improve bilateral relations and promote bilateral friendly exchanges has important practical significance.

\section{Japanese Intercultural Communication Research Significance}

Since the normalization of Sino-Japanese diplomatic relations, in general, bilateral relations have gradually eased, although toward the positive direction, but the development process of twists and turns. In recent years, with the rapid development of the world economy, exchanges between countries also were frequent, and Japan as a neighboring country, in economic and political contacts also on deepening the same time, dealing with bilateral relations between the two countries, not only concerned about the interests of political and economic factors, but also increasingly concerned about the deep cultural similarities and differences between the two countries.

China and Japan both economically and exchanges in political culture is actually cross-cultural communication, cross-cultural communication between the two countries at the time, should not be ignored in the Japanese culture and customs similarities and differences. The reaction not only cultural values of a folk, but also restricts people's relationships, anyone can be affected by culture. If we can increase people's knowledge of cross-cultural communication, people communicative motivation will be greatly increased. If people can actively participate in communication, both can learn a lot of valuable experience and knowledge, but also to cultivate the development of communicative competence.

People carrying out cross-cultural communication, often there will be some obstacles phenomenon. First, people often use their own cultural values to measure analyze cultural phenomena in other countries, and national culture mistaken other countries the same. Secondly, although we do not have contact with other cultures and some countries, but our brain has formed a preconceived impression, for example, the Japanese worked very hard, romantic French, the Americans just like, these phenomena is a stereotype, also known as stereotypes. Third, the misunderstanding awareness on people from different cultural backgrounds during cross-cultural communication is very easy to make such a mistake, mistaken for each other and their own, due to the erroneous understanding, once found each other's behavior and their own understanding different, it will confused, disappointed. Therefore, we should actively learn to recognize multiculturalism, and to clearly understand the differences between different cultures and their own culture, to avoid cultural conflicts and promote bilateral friendly exchanges. Chinese language teaching in Japan during the Sino-Japanese cultural interaction between the Chinese teachers teaching strategies, level of learning Japanese students, are profoundly affected Fusion Japanese culture. We must treat equally and Japanese culture, and Japanese cultural similarities and differences in analytical, consciously establish Chinese cultural outlook, gradually forming a double cultural identity, so as to carry out the Sino-Japanese Intercultural Communication smoothly.

\section{Necessity of Sino-Japanese intercultural communication}

Each nation's geographical location, historical development, environment, social structure and religion and other external environment is different, so each nation to form a unique customs and culture, language and other contextual factors, people from the same cultural backgrounds speak voice and speech habits have distinctive features. When people from different cultural backgrounds to communicate, both accustomed to using their own way of thinking to understand the meaning expressed by the other side, resulting in communication between the two sides in conflict. In the 1960s, the United States opened a cross-cultural study of its kind, which is an emerging discipline, main communication culture. Its purpose is to determine the study of language and cultural ties, the purpose is to make the voice quality of teaching improved, ultimately successful intercultural communication. 
Scholars and Japanese Intercultural Communication Research time is very short, about ten years, but during this period, has undergone dramatic changes, and these changes will undoubtedly change and its neighboring disciplines have developed a close relationship. Its neighboring disciplines varied, with linguistics, grammar, pragmatics, anthropology, languages, psychology, education, sociology, philosophy, cultural studies, social psychology ...... they give and Japanese Intercultural Communication Science provides a theoretical basis. Japanese culture has a very clear national character is, of course, the Sino-Japanese cultural patterns presented in different forms, and this difference is reflected in the culture, including the Sino-Japanese values, behavior, language performance, different rituals and so on in Study of Intercultural communication between China and Japan should not only take into account the differences between the two cultures, but also to conduct a comprehensive study.

\section{Japanese study intercultural communication purposes}

Intercultural Communication Studies and Japanese people to Japanese culture aimed at avoiding biased views, train people hold a positive attitude to look at to understand Japanese culture. The Japanese culture there is a difference, we want to be good at digging differences were found between the two sides, so you can deepen understanding of their own culture, and it is possible to relatively objective understanding between cultural connotations and characteristics. Japanese Intercultural Communication Research also focus on training the ability to cross-cultural adaptation time. When first contact with Japanese culture, often feel a great cultural differences, resulting in communication barriers, resulting in a state of some inappropriate. To avoid communication conflict, and finding ways to slow down cultural misunderstandings, to study cross-cultural knowledge and improve cross-cultural communication ability to adapt. Cross-cultural research in Japan also attaches great importance to cross-cultural communication skills development. With the advent of the information age, the degree of opening up countries are gradually expanding, study abroad or travel across the international trade of these people has increased every year, they have mastered the necessary cross-cultural communication skills, avoid cultural conflict, overcome cultural shock phenomenon. Currently, the University of Japan, the United States has already set up related courses, in addition, the community also set up a special cross-cultural communication ability to adapt to the culture of educational institutions, which greatly adapted to the international development trend. Practical significance of Sino-Japanese intercultural communication is far greater than its theoretical significance.

Normal maintenance and development of Sino-Japanese relations are far-reaching, not only affect the economic development and social stability in the Asia-Pacific region and Japan, but also for the stability and development of the whole world have a significant impact. Cultural Differences from day to find out the date of Chinese Teaching in solving strategies, the two sides after a long-term cooperation and friendly exchanges, to resolve the contradictions of history it has practical significance right. Sino-Japanese relations and co-existing conflicts. Strive to maintain and improve Sino-Japanese relations is the Sino-Japanese two parties bounden duty, and to strengthen the Sino-Japanese cultural exchange is a crucial starting point. Since ancient times in China and Japan there are many cultural similarities, cultural exchange is more likely to cause resonance and Japanese nationals, which would also serve for the friendly cooperation between China and Japan has laid a good emotional foundation. In fact, the relationship between the economy, culture and politics are complementary, cultural blend of friendly exchanges between Chinese and Japanese political economy and lay the cornerstone, can be seen, the cultural differences between Japan and the conflict of promoting the development of Sino-Japanese relations have far-reaching meaning.

\section{Analysis of Cultural Differences between Chinese and Japanese}

Language is the carrier of culture, culture is the basis of language, language as a constraint. Different languages have different cultural backgrounds of each country's culture will affect the 
language of the country. China and Japan in different historical background, living environment, lifestyle, values, etiquette and form are different. Learning a foreign language cannot be separated for their own and other cultures of learning and understanding, only be able to fully understand the culture of the target language country, it can only be mastered under the premise of the target language country grammar, pronunciation, and very skilled cross-cultural communication. Similarly, in the Chinese language teaching in Japan, understand Japanese culture and Japanese culture background and similarities and differences are very important. For Chinese learning Japanese, Chinese and when interacting with the Chinese people, is bound to encounter language barriers and cultural conflicts. Language communication problems, you can master through learning. But people do not understand the Chinese way of thinking, behavior, and customs, use their own thinking to understand the Chinese words, which can easily lead to conflict between the two sides. Therefore, in teaching Chinese to Japan, the Chinese students in the importance of learning Chinese, we should also take into account the learning Chinese culture, Chinese spoken during practice, to avoid interference with Japanese language and culture, according to Chinese thinking for effective cross-cultural communication.

Japanese teaching goal is to enable foreign students can skillfully use the target language to communicate. Japanese teaching in order to live in the Chinese students and Chinese cultural circle of Chinese people to build up, Japanese, Chinese teachers should not only allow students to learn Chinese language, but also learning Chinese carried by Chinese culture. In fact, Chinese students when making cross-cultural communication, not only in language skills by a certain challenge, but also in cultural understanding has also been a challenge. China and Japan's values, ways of thinking and living habits, the Chinese students are very difficult to complete the task of communication, therefore, develop Chinese students' intercultural communicative competence of Japanese teaching is an important task, the key is to continue to help Chinese Japanese teacher improve student understanding, acceptance and treatment levels and Japanese cultural differences.

Thus, the Japanese teacher should show the cultural differences of Chinese students in Japan exists objectively, let Chinese students to recognize the fact that there are differences in the day to inform them of the existence of diverse cultures in the world, every culture there are differences. To learn a new language, we must understand and accept cultural differences.

\section{Grammar Problems and Solutions}

In addition to voice, the Japanese learning Chinese grammar is another problem. Although the Japanese have a lot of characters, but the difference is still very large Chinese Japanese grammar, it cannot be ignored. In terms of word order, mainly in the Chinese SVO based, while the Japanese to SOV-oriented. Therefore, the Japanese students often say, "I drink", "My way to go" and so on. In teaching the Japanese grammar, telling them the basic premise of word order in Chinese institutions and usage, and more speaking practice, student teachers in a timely manner to correct the problem of word order. In addition, teachers should design the appropriate exercises, through repeated practice the same kind of word order to gradually change the set thinking. In temporal terms, when the Chinese state is very flexible, and when the Japanese state is relatively fixed. Therefore, teachers should conduct a comprehensive summary, based on practice, theory with practice, the students combine different situations, individualized, so that students are encouraged to speak Chinese as much as possible in life, combined with the acquisition of Chinese learning, so that students learn with a new temporal knowledge free conversation practice, through a lot of practice, testing whether students truly master the consolidation of the state of knowledge hours, but in the process also allows the students themselves which summarized the grammar rule.

"Character is the record of Chinese writing symbol system, it is the ancestor of the Han people in long-term social practice gradually created." Character is constituted by a stroke, since ancient times, Chinese writing strokes are basic rules. Usually after the first horizontal, vertical, downwards-right, after the first, from top to bottom, left to right. Character smooth vertical and horizontal features requires us to focus on writing neat, a painting. Although there are many Japanese characters, but 
there are a lot to absorb a lot of foreign words, many of which are a complete, leading Japanese students in writing Chinese characters, often even written in pen. Relative speech grammar learning the Japanese Chinese character writing is relatively easy. When professors write Chinese characters, the teacher on the blackboard to write a stroke, students following a stroke followed write, after teachers can lead students to practice their repeated gestures. At the same time, teachers can dictate the students study in the classroom when the end of the consolidation exercise homework again. In addition, teachers can also show through courseware to students or download videos and students share a piece of writing Chinese characters, so that students better grasp of writing Chinese characters.

\section{Summary}

With the rapid development of transportation and communications equipment, different nationalities, different countries from around the world have more frequent contacts and contacts, cross-cultural communication attracted worldwide attention, more countries began to study cross-cultural communication, but, when the cross-cultural communication proceed smoothly is not easy, it requires not only both parties truly understand each other and be able to reach consensus in some areas, including the understanding of each other's geographical environment, customs, language expression, values, thinking Information and cultural background. But for the communication itself and that the meaning of the language and are familiar with each other's non-verbal form of expression is the key to the success of cross-cultural communication.

For Japanese study Chinese in China, not only to learn the Chinese language, but also through the acquisition of Chinese to understand Chinese culture, to understand the full range of knowledge and social development and economic development, which is what most Chinese learners purpose. Therefore, in the side of learning Chinese, we need to deliberately to learn Chinese culture, society, economy and technology. In the Han Dynasty, China and Japan began contacts, cultural exchanges China's long history, but, regardless of geography or national identity of China and Japan there are significant differences, Sino-Japanese twin distinctive culture, thus before we conduct cross-cultural communication, you need to understand the differences between Chinese and Japanese culture, to increase the ability to adapt to the culture of each country, to hold both cultural objective and rational attitude, which is not to say let's go to accept the double culture, but at least emotion not biased. When the Japanese exchanges, as far as possible in accordance with the way of thinking and language habits of each other to understand each other, so as to avoid double misunderstanding, smooth communication purposes.

\section{References}

[1] Li Chen. On the Sino-Japanese cultural differences reflected in interpersonal communication. Next-generation, 2010 (6)

[2] Jiang Jinfang. Chinese and Japanese Cultural Differences in Intercultural Communication. Mudanjiang Teachers College, 2010 (3)

[3] Jiang Xiaoping, Intercultural Communication Dynasty. Social Sciences. 2012 (5)

[4] But sea sword, Chen Lei. Intercultural Communication and the formation process of the conflict. Wuhan University of Technology. 2006 (3)

[5] Wang Qun. Intercultural Communication Disorder Causes and Countermeasures. China Adult Education "2005 (7)

[6] Jiang Luyang. Sino-Japanese cultural conflict brought enlightenment Foreign Teaching Chinese. Jiannan literature. 2011 (10)

[7] Yanju segment. And Japanese Intercultural Communication Pragmatic Failures and Culture interruption. Changchun Normal University. 2012 (5) 
[8] Xu Mingling. Language expressions in Japanese and Japanese cross-cultural differences in teaching. ADULT EDUCATION INSTITUTE. 2011 (6)

[9] Guan Shijie. On cross-cultural issues in the daytime. International Politics. 2000 (2)

[10] Chen Yan. On Sino-Japanese disturbances in their own culture and cross-cultural mother tongue. Japanese learning and research. 2004 (4)

[11] Su Jing. Situation and Prospects Learning Chinese in Japan. Yunnan Normal University. 2009 (2)

[12] Wangqiu Hong. And Japanese Intercultural Communication Cultural Misreading. Jiamusi Education Institute. 2012 (6) 